\title{
Environmental Quality and Its Attendant Effect on Human Health: New Evidence from Panel Quantile Regression for Anglophone Countries in West Africa
}

\author{
Aduralere Opeyemi Oyelade, Olamide David Tijani, Mumini Oluwaseyi Wakile, \\ Adeyemi Lookman Kanimodo \\ Department of Economics, University of Ibadan, Ibadan, Nigeria \\ Email address: \\ E011962.oyelade@dlc.ui.edu.ng (A. O. Oyelade), adontopdominating@gmail.com (A. O. Oyelade), olamidedav5@gmail.com (O. D. Tijani), \\ megawake424@gmail.com (M. O. Wakile),kantrons@gmail.com (A. L. Kanimodo)
}

\section{To cite this article:}

Aduralere Opeyemi Oyelade, Olamide David Tijani, Mumini Oluwaseyi Wakile, Adeyemi Lookman Kanimodo. Environmental Quality and Its Attendant Effect on Human Health: New Evidence from Panel Quantile Regression for Anglophone Countries in West Africa. International Journal of Immunology. Vol. 8, No. 4, 2020, pp. 89-95. doi: 10.11648/j.iji.20200804.14

Received: December 27, 2019; Accepted: January 6, 2020; Published: December 28, 2020

\begin{abstract}
An estimated seven million people per year die from emission-related diseases. These include stroke and heart disease, respiratory illness and cancers. Many health-harmful emission pollutants also damage the climate and reducing emission pollution would save lives and help slow the pace of near-term climate change. This study investigated the environmental quality and its attendant effect on human health from Anglophone countries in West Africa over the period of 1990 to 2013 using panel quantile regression. The result obtained showed that the $\mathrm{CO}_{2}$ emission that can affect the health of Anglophone countries in West Africa are $\mathrm{CO}_{2}$ emissions from gaseous fuel consumption, $\mathrm{CO}_{2}$ emissions from liquid fuel consumption, $\mathrm{CO}_{2}$ emissions from residential buildings and commercial and public services, $\mathrm{CO}_{2}$ emissions from solid fuel consumption, $\mathrm{CO}_{2}$ emissions from transport. Other control variables that have influence on human health were health expenditure, mortality rate and fertility rate. Therefore, the policy makers should implement policies (like energy conservation policies) that will control emission from gaseous fuel consumption, emissions from liquid fuel consumption, emissions from residential buildings and commercial and public services, emissions from solid fuel consumption and emissions from transport. Also, health sector has to be properly cater for by spending more on health and this can only increase the health outcomes in a country.
\end{abstract}

Keywords: Life Expectancy, $\mathrm{CO}_{2}$ Emissions, Panel Data Analysis, Panel Quantile Regression

\section{Introduction}

An estimated seven million people per year die from emission-related diseases. These include stroke and heart disease, respiratory illness and cancers. Many health-harmful emission pollutants also damage the climate and reducing emission pollution would save lives and help slow the pace of near-term climate change. The increasing deterioration in environmental quality across the world is bringing out serious challenge to healthy living along with the increasing threat of global warming. Given the current debates on global warming, environmental problems, the relationship between the environment and health outcomes are getting more attention for economic policy makers [1]. Environmental consequences of global warming and greenhouse gas emissions increase the concerns of the consumption of fossil fuels. Environmentalists as well as policy makers are concerned about the air pollution. Especially, air pollution from rapid industrialization and the use of energy has been recognized to be a cause of serious health problem. Particularly, sulphur dioxide and carbon dioxide emissions from burning of fossil fuels are contributing significantly to pollution. In fact carbon dioxide, a greenhouse gas is considered to be a major contributor to global climate change, which has been a topical issue among policy makers and focus of quite a number of researches across different fields of study [2].

Although, there are lot of research work that has been done 
in this area $[1,3-8]$. This study identifies some gaps in the literature based on the past studies in this area. Firstly, past studies only considered aggregated data on $\mathrm{CO}_{2}$ emission except for few work like [1] that break the emission into $\mathrm{CO}_{2}$ emissions from the consumption of coal, from the consumption of natural gas and from the consumption of petroleum. These are not the only emission that can be considered and this is one of the identified gaps that this study is set to full by considering $\mathrm{CO}_{2}$ emissions from electricity and heat production, from gaseous fuel consumption, from liquid fuel consumption, from manufacturing industries and construction, from other sectors, excluding residential buildings and commercial and public services, from residential buildings and commercial and public services, from solid fuel consumption and from transport. Also, this study will make used of quantile regression which has become an important and popular empirical research tool to study the conditional response distribution in regression. The general path for deriving quantile regressionis based on the standard linear model and quantile regression is achieved by extending the median case to all other arbitrary quantiles.

The rest of this article is organized in four sections. Section 2 reviews the theoretical underpinning and literature review. Section 3 is devoted to the estimation technique, data source and variables measurement. Section 4 presents the discussion of results and Section 5 concludes the study.

\section{Theoretical Underpinnings and Literature Review}

The health implications of $\mathrm{CO}_{2}$ emission can be better understood using the externality theory. An externality is present whenever the wellbeing of a consumer or production possibilities of a firm is/are directly affected by the actions of another agent in the economy. A consumer or firm may in some circumstances be directly affected by the actions of other agents in the economy; that is, there may be external effects from the activities of other consumers or firms. For example, a range of external costs is associated with $\mathrm{CO}_{2}$ emission with on overall effect on the health of the people and value of surrounding properties. Externality can be one of two types: simple bilateral externality, which is the simplest possible externality, and multilateral externalities. Simple bilateral externality is the one that involves only two agents in the economy, where one of the agents engages in an activity that directly affects the other. In most cases, externalities are generated and felt by numerous parties. This is particularly true of those externalities, such as pollution, smog caused by automobile use, or congestion, that are widely considered to be important policy problems.

Numerous studies have been conducted on the relationship between environmental quality and its attendant effect on human health. For instant, [1] tests for the presence of the causality relationships among of life expectancy at birth, carbon dioxide emissions in terms of the source of consumption, total health expenditures and education for sample of 25 EU member countries (Austria, Belgium, Bulgaria, Czech Republic, Denmark, Estonia, Finland, France, Germany, Greece, Hungary, Ireland, Italy, Latvia, Lithuania, Luxembourg, the Netherlands, Poland, Portugal, Romania, Slovenia, Slovakia, Spain, Sweden and United Kingdom) covering the period 1995 to 2013. This study utilized panel data analysis and the result showed that there exists a bidirectional causal relationship between life expectancy and all the other explanatory variables, except for carbon dioxide emissions consumption from coal. Similarly, there was a bidirectional causal relationship between health expenditures and other variables, except for carbon dioxide emissions from consumption of coal. Moreover, it is observed that there exists causal relationships among health, education and environmental quality, is proxied by carbon dioxide emissions in terms of consumption coal, natural gas and petroleum. This also shows that environmental quality could be considered as a constraint for economic growth, is related to the causes of education and the quality of human life in EU-25 member countries.

Also, [3] estimated the effect of industrial pollution on public health in Nigeria using time series data sourced from World Development Indicators (WDI) data from 1971-2011. The study employed the 'theory of externality'. In the same vein, the study utilized VECM technique. The VECM shows a negative relationship between life expectancy (a proxy for public health) and carbon dioxide emission (industrial pollution) both in the short and long run. The coefficient of error correction term $(-0.0802)$ of the model was significant and negative meaning that the system corrects its previous period disequilibrium at a speed of approximately $8 \%$ annually. The impulse response analysis revealed that after the first quarter, a one standard deviation shock in carbon emission has a negative and significant impact on life expectancy, thereby validating the negative relationship between life expectancy and carbon dioxide emission in Nigeria.

Furthermore, [6] used time series data from 1985 to 2016 to examine the long-run effect of emissions of greenhouse gas (GHG) on health outcomes in Nigeria engaging the autoregressive distribution lag (ARDL) econometric approach to co-integration. The ARDL estimations deduced that activities of humans cause harmful effect to health, as changes in atmospheric GHG concentrations will affect the amount of energy stored in the atmosphere, also it was observed that human activities increase GHG to the atmosphere, this is through combustion of fossil fuels and $\mathrm{CO}_{2}$, and there are two major sources of GHG emissions (GHGE). When the quantity of carbon dioxide increases in the air, more heat is stored in the atmosphere; and this comes upon human beings thereby causing a great harmful effect to human health. The result from ARDL econometric approach to co-integration shows that $1 \%$ increase in GHGE reduces life expectancy by $0.0422 \%$ which is used as a proxy for health outcome, if this happens, invariably, mortality rate will be 146.6 . The results also shows that $1 \%$ increase in government health care 
expenditure increases life expectancy approximately by $18.10 \%$.

In the same manner, [9] examined how people's perceptions about local environmental quality (poor water, poor air, and poor sanitation/sewer) and global environmental quality (global warming, loss of animal and plant species, and pollution of water bodies) are correlated with their wellbeing in a cross-country sample using data from the World Values Survey. We find a negative correlation between perceptions about the poorness of local environmental quality and subjective well-being for both developed and African countries. However, only in developed countries is there a negative correlation between perceptions about the poorness of global environmental quality and subjective well-being.

Also, [10] examined the effects of environmental degradation, institutional quality, and other macroeconomic variables on health using a panel data from 45 African countries over the period 1995-2015. The empirical analysis was carried out using the GMM method to solve the problem of endogenous variables. Findings demonstrated that there was a negative relationship between environmental degradation and health on one hand, and a positive relation between institutional quality and health on the other hand. Moreover, the direct and negative effects of environmental degradation on health may be decreased by the indirect and positive effects through institutions quality and macroeconomic variables.

Moreover, [11] examined the environmental factors affecting health indicators in Sub-Saharan African countries. The study utilized number of environmental factors including carbon dioxide emissions, energy use, fossil fuel energy consumption, land used under cereal production, household final consumption expenditures and water sanitation facility that have a promising impact on African's health. The study considered four health variables including external resources for health, health expenditures per capita, life expectancy at birth and out-of-pocket expenditures for seven selected SubSaharan African countries namely, Botswana, Cameroon, Kenya, Nigeria, Senegal, South Africa and Sudan for panel data estimations, over the period of 1995-2013. The results confirmed that environmental factors affect the African's health i.e., carbon dioxide emissions increases the health expenditures per capita, while it decreases the external resource of health in a region. Fossil fuel energy consumption increases the external resources of health and life expectancy while it decreases the out-of-pocket expenditures of the African countries. Life expectancy significantly decreases the external resource of health. Finally, inadequate water sanitation increases the healthcare expenditures while it decreases the external resources of health and life expectancy in Sub-Saharan African countries.

Also, [12] modeled the nexus between health expenditure (HE), environmental pollution $\left(\mathrm{CO}_{2}\right.$ emissions; Nitrous oxide emissions) and economic growth in the Sub-Saharan Africa countries using annual data over the period 1990-2015. The study applied the estimation method ARDL to model the long run and short run. In addition, the study used the VECM
Granger causality test for checking the direction of causality. Firstly, the results of ARDL test indicated that economic growth has positive impact on the $\mathrm{HE}$ while $\mathrm{CO}_{2}$ emissions and NOE have negatives impact on the HE in the long run. The results showed that a $1 \%$ increase in per capita GDP will lead to a $0.332 \%$ increase in the health expenditure, but an increase in $\mathrm{CO}_{2}$ emissions and NOE of $1 \%$ will decrease the HE by $0.066 \%$ and $0.577 \%$, respectively. On the other hand, the results of the VECM Granger causality show that there is a one-way relationship going from the HE to GDP per capita. On the contrary, a two-way causality relationship between $\mathrm{CO}_{2}$ emissions and GDP per capita and also between the HE and $\mathrm{CO}_{2}$ emissions is found.

Furthermore, [13] investigated the extent to which environmental hazards affect the life expectancy in Africa using Nigeria time series data spanning from 1960 to 2017. The study adopted generalized autoregressive conditional heteroscedasticity $(\mathrm{GARCH})$ model in estimating the total number of 58 (years) observations to ensure robustness in the estimation results. The estimation results showed that environmental hazards in terms of carbon dioxide $\left(\mathrm{CO}_{2}\right)$ emission from solid fuel consumption reduce life expectancy (LEX) by 1 month and 3 weeks with a statistically significant result. Also, income, as proxied by GDP, extends LEX by 1 year 6 months with statistically insignificant result, while population growth (POPG) equally extends LEX by 5 years 5 months due to increase in human resource/manpower which enhances agricultural productivity in Africa. Based on the empirical findings, there is a need for the African Union (AU) to adopt a policy regulating the excessive $\mathrm{CO}_{2}$ emission from solid fuel consumption to ameliorate the negative consequences it exerts on the lifespan of the African population. Also among other policy recommendations, the economies in Africa should increase budgetary allocations to science and technology sector to drift the economies from solid fuel consumption to more robust electricity/digital driven technology and hybrid-energy efficient mechanisms.

In the same vein, [14] studied the effects of $\mathrm{CO}_{2}$ emission on economic growth, urbanization, energy consumption, life expectancy and welfare of Middle East and North African (MENA) countries which includes Algeria, Bahrain, Egypt, Emirates Arabs, Jordan, Saudi Arabs, Morocco, Qatar, Tunisia, and Yemen between 1999 and 2010. The study adopted the fully modified ordinary least squares (FMOLS) and dynamic ordinary least squares (DOLS) in investigating both the short and long effects of the study objectives. However, the result shows that life expectancy is influenced negatively by the $\mathrm{CO}_{2}$ emissions in both the short and long run of all the MENA countries. The result equally reveals that $\mathrm{CO}_{2}$ emissions are positively influenced by energy consumption per capita and statistically significant. The result also noted that income per capita affects $\mathrm{CO}_{2}$ emission negatively in the long run as a result of the activities of the nonpolluting sector and economic strategies of the MENA countries.

Lastly, [15] examined the role of environmental quality 
and life expectancy in determining per capita health expenditures of the Organization for Petroleum Exporting Countries (OPEC) for the period covering 2000 to 2010. The result reveals that an increase in $\mathrm{CO}_{2}$ emissions increases health expenditures, whereas a rise in life expectancy at birth decreases health expenditures in short-run. [16] utilized symmetrical ARDL model in determining the impact of energy consumption on the growth in Nigeria from 1986 to 2016. The result from the symmetrical ARDL highlighted that due to constant fluctuations in the electricity supply, growth in Nigeria has not recorded any significant improvement. The findings of the study equally pointed out that gas consumption in Nigeria has not impacted positively on the economy due to activates of gas flaring and other environmental pollutants in some major oil-producing states in the Niger-Delta region. On the contrary, the result indicated that petroleum consumption contributes positively to the growth of the Nigerian economy contrary to gas consumption.

\section{Estimation Technique, Data Source and Variables Measurement}

The study make used of quantile regression technique that was introduced in the seminal paper by [17]. Whereas the method of least squares results in estimates of the conditional mean of the response variable given certain values of the predictor variables, quantile regression aims at estimating either the conditional median or other quantiles of the response variable and it is use when the conditions of linear regression are not applicable. Quantile regression is desired if conditional quantile functions are of interest. One advantage of quantile regression, relative to the ordinary least squares regression, is that the quantile regression estimates are more robust against outliers in the response measurements. However, the main attraction of quantile regression goes beyond that. Different measures of central tendency and statistical dispersion can be useful to obtain a more comprehensive analysis of the relationship between variables.

Let $\mathrm{Y}$ be a real valued random variable with cumulative distribution function $F_{Y}(y)=P(Y \leq y)$. The $\tau^{\text {th }}$ quantile of $\mathrm{Y}$ is given by

$$
Q_{Y}(\tau)=F_{Y}^{-1}(\tau)=\inf \left\{y: F_{Y}(y) \geq \tau\right\}
$$

Where $\tau \in(0,1)$.

Defining the loss function of life expectancy due to $\mathrm{CO}_{2}$ emission as $\rho_{\tau}(y)=y\left(\tau-\Pi_{(y \prec 0)}\right)$, where $\Pi$ is an indicator function. A specific quantile can be found by minimizing the expected loss of life expectancy due to $\mathrm{CO}_{2}$ emission $Y-\varepsilon$ with respect to $\varepsilon$ :

$$
\min _{\varepsilon} E\left(\rho_{\tau}(Y-\varepsilon)\right)=\min _{\varepsilon}\left\{(\tau-1) \int_{-\infty}^{\varepsilon}(y-\varepsilon) d F_{Y}(y)+\tau \int_{\varepsilon}^{\infty}(y-\varepsilon) d F_{Y}(y)\right\} .
$$

This can be shown by setting the derivative of the expected loss function of life expectancy due to $\mathrm{CO}_{2}$ emission to 0 and letting $q_{\tau}$ be the solution of

$$
0=(1-\tau) \int_{-\infty}^{q_{\tau}} d F_{Y}(y)-\tau \int_{q_{\tau}}^{\infty} d F_{Y}(y) .
$$

This equation reduces to

$$
0=F_{Y}\left(q_{\tau}\right)-\tau \text {, and then to } F_{Y}\left(q_{\tau}\right)=\tau \text {. }
$$

Hence $q_{\tau}$ is $\tau^{\text {th }}$ quantile of the random variable $\mathrm{Y}$.

The $\tau$ sample quantile can be obtained by solving the following minimization problem

$$
\begin{gathered}
\hat{q_{\tau}}=\underset{q \in \Re}{\arg \min } \sum_{i=1}^{n} \rho_{\tau}\left(y_{i}-q\right), \\
\hat{q_{\tau}}=\underset{q \in \Re}{\arg \min }\left[(\tau-1) \sum_{y_{i \prec q}}\left(y_{i}-q\right)+\sum_{y_{i \geq q}}\left(y_{i}-q\right)\right]
\end{gathered}
$$

where the function $\rho_{\tau}$ is the tilted absolute value function. The intuition is the same as for the population quantile.

The data for empirical analysis in this study is extracted from World Development indicators (WDI) and spanned over the period 1990-2013 from West Africa Anglophone

\begin{tabular}{|c|c|c|c|}
\hline Variable Name & Identifier & Source of Data & Definition and Measurement \\
\hline Human Health & $\mathrm{HH}$ & WDI, 2017 & $\begin{array}{l}\text { Human health measured by life expectancy at birth, total } \\
\text { (years) }\end{array}$ \\
\hline $\begin{array}{l}\mathrm{CO}_{2} \text { emissions from electricity and heat } \\
\text { production }\end{array}$ & $\mathrm{CO}_{2} \mathrm{EHP}$ & WDI, 2017 & $\begin{array}{l}\mathrm{CO}_{2} \text { emissions from electricity and heat production, total (\% } \\
\text { of total fuel combustion) }\end{array}$ \\
\hline $\mathrm{CO}_{2}$ emissions from gaseous fuel consumption & $\mathrm{CO}_{2} \mathrm{GFC}$ & WDI, 2017 & $\mathrm{CO}_{2}$ emissions from gaseous fuel consumption ( $\%$ of total) \\
\hline $\mathrm{CO}_{2}$ emissions from liquid fuel consumption & $\mathrm{CO}_{2}{ }_{-} \mathrm{LFC}$ & WDI, 2017 & $\mathrm{CO}_{2}$ emissions from liquid fuel consumption (\% of total) \\
\hline $\begin{array}{l}\mathrm{CO}_{2} \text { emissions from manufacturing industries } \\
\text { and construction }\end{array}$ & $\mathrm{CO}_{2} \_\mathrm{MIC}$ & WDI, 2017 & $\begin{array}{l}\mathrm{CO}_{2} \text { emissions from manufacturing industries and construction } \\
\text { (\% of total fuel combustion) }\end{array}$ \\
\hline $\begin{array}{l}\mathrm{CO}_{2} \text { emissions from other sectors, excluding } \\
\text { residential buildings and commercial and public } \\
\text { services }\end{array}$ & $\mathrm{CO}_{2} \_\mathrm{OTHER}$ & WDI, 2017 & $\begin{array}{l}\mathrm{CO}_{2} \text { emissions from other sectors, excluding residential } \\
\text { buildings and commercial and public services ( } \% \text { of total fuel } \\
\text { combustion) }\end{array}$ \\
\hline $\mathrm{CO}_{2}$ emissions from residential buildings and & $\mathrm{CO}_{2} \mathrm{RBCPS}$ & WDI, 2017 & $\mathrm{CO}_{2}$ emissions from residential buildings and commercial and \\
\hline
\end{tabular}
countries which are Gambia, Sierra Leone, Liberia, Ghana and the most populous African country Nigeria but Sierra Leone were excluded because data were not available for some variables in Sierra Leone.

Table 1. Variables, Data Sources and Measurement. 


\begin{tabular}{llll}
\hline Variable Name & Identifier & Source of Data & Definition and Measurement \\
\hline commercial and public services & & & public services (\% of total fuel combustion) \\
$\mathrm{CO}_{2}$ emissions from solid fuel consumption & $\mathrm{CO}_{2}$ SFC & WDI, 2017 & $\mathrm{CO}_{2}$ emissions from solid fuel consumption (\% of total) \\
$\mathrm{CO}_{2}$ emissions from transport & $\mathrm{CO}_{2}$ TRANS & WDI, 2017 & $\mathrm{CO}_{2}$ emissions from transport (\% of total fuel combustion) \\
Health expenditure & $\mathrm{HE}$ & WDI, 2017 & Health expenditure, total (\% of GDP) \\
Mortality rate & $\mathrm{MR}$ & WDI, 2017 & Death rate, crude (per 1000 people) \\
Fertility rate & $\mathrm{FR}$ & WDI, 2017 & Fertility rate, total (births per woman) \\
Population growth & $\mathrm{PG}$ & WDI, 2017 & Population growth (annual \%) \\
GDP per capita growth & GDPPCG & WDI, 2017 & GDP per capita growth (annual \%) \\
\hline
\end{tabular}

Source: Authors' compilation using Word Bank WDI data set, 2017.

\section{Discussion of Results}

Figure 1 depicted the life expectancy in Anglophone countries in West Africa. Life expectancy is representing of the quality of life in a country, since individuals can hope to live longer, fuller lives. It is an estimate of an individual's life span derived from averaging the age all individuals who die in a particular year [18]. According to [19], Nigeria population was 200,963,599, Ghana population was $30,417,856$, Liberia population was 4,937,374 and Gambia population was $2,347,706$. It could be observed that despite the fact that Nigeria population can swallow all the population of over countries within the Anglophone countries in West Africa three times but it has the lowest life expectancy indicating that population increase without improvement in living standard are detriment to health of the citizen as well as their average number of years that they will live up to. The highest life expectancy in Nigeria was recorded in 2013 as 52.44 meaning that an average Nigerian live up to 52.44 years on the average. Ghana has the highest life expectancy throughout the years follow by Liberia and Gambia. People in Ghana can live up to 61.14 year and Liberia people can live up to 60.52 years while Gambia people can live up to 59.99 years.

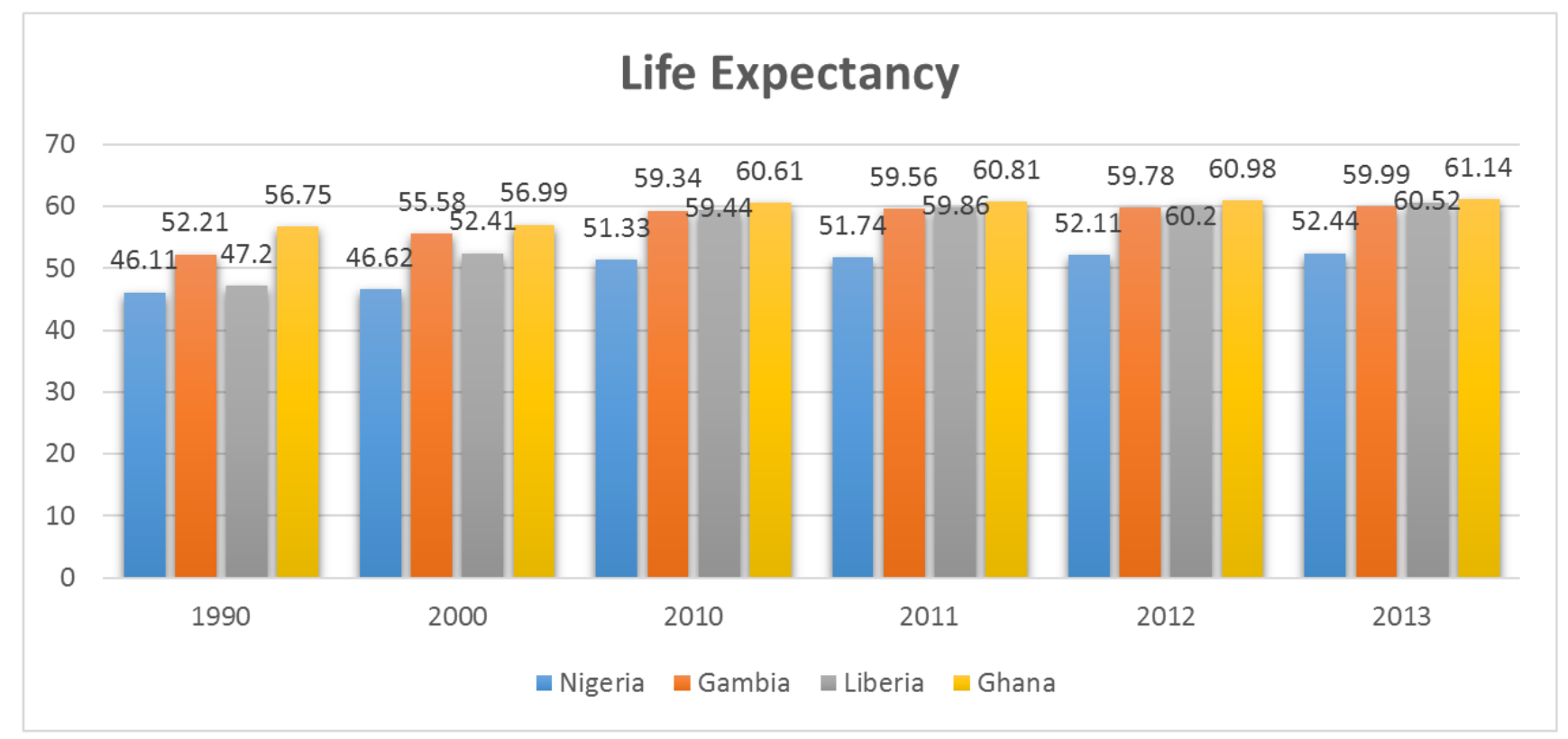

Source: Authors' compilation using Word Bank WDI data set, 2017.

Figure 1. Stylist Fact about Life Expectancy in Anglophone Countries in West Africa.

Both pooled descriptive statistics, OLS and quantile regression estimates were reported below Tables 2-3. Descriptive statistic is used to summarize the data, OLS estimates provide a baseline of mean effects and the study compare these to estimates for separate quantiles in the conditional distribution of $\mathrm{CO}_{2}$ emissions. The study report results for the $10^{\text {th }}, 25^{\text {th }}, 50^{\text {th }}, 75^{\text {th }}$ and $90^{\text {th }}$ quantiles.

Table 2 gives some descriptive statistics of the data. As can be seen, there are some variations in the data among the panel countries. Population has the highest yearly mean of 74613 while $\mathrm{CO}_{2}$ emissions from solid fuel consumption has the lowest mean. Also, all the variables fall within their mean and human health, $\mathrm{CO}_{2}$ emissions from liquid fuel consumption, $\mathrm{CO}_{2}$ emissions from transport and fertility rate are negatively skewed while others are positively skewed. The Kurtosis exceeds 3 in most cases suggesting that series have heavy tails while Kurtosis less than 3 means light tails. This shows that data is not normal which is also proved with the Jarque-Bera test statistic. Therefore, estimation technique based on linear Gaussian models will be biased, hence it more appropriate to use quantile regression technique. 
Table 2. Descriptive Statistics.

\begin{tabular}{|c|c|c|c|c|c|c|c|}
\hline Variables & Observation & Mean \pm SD & Minimum & Maximum & Kurtosis & Skewness & JB \\
\hline $\mathrm{HH}$ & 96 & $54.096 \pm 4.776$ & 46.073 & 61.142 & 1.795 & -0.334 & 7.599 \\
\hline $\mathrm{CO}_{2}$ EHP & 96 & $154.910 \pm 248.348$ & 0.833 & 1030.427 & 5.473 & 1.858 & 79.685 \\
\hline $\mathrm{CO}_{2} \_\mathrm{GFC}$ & 96 & $18.336 \pm 21.587$ & 0.135 & 75.226 & 2.538 & 0.855 & 12.558 \\
\hline $\mathrm{CO}_{2} \_\mathrm{LFC}$ & 96 & $68.345 \pm 25.588$ & 17.675 & 100.0 & 1.557 & -0.385 & 10.710 \\
\hline $\mathrm{CO}_{2}{ }_{-} \mathrm{MIC}$ & 96 & $136.119 \pm 236.330$ & 4.250 & 968.088 & 5.230 & 1.798 & 71.639 \\
\hline $\mathrm{CO}_{2}$-OTHER & 96 & $6.785 \pm 15.768$ & -13.446 & 143.137 & 60.111 & 7.002 & 13831.2 \\
\hline $\mathrm{CO}_{2}$ RBCPS & 96 & $8.941 \pm 6.941$ & 0.376 & 26.487 & 2.205 & 0.416 & 5.293 \\
\hline $\mathrm{CO}_{2}$ TRANS & 96 & $33.638 \pm 22.745$ & 0.205 & 66.791 & 1.700 & -0.447 & 9.957 \\
\hline $\mathrm{HE}$ & 96 & $5.667 \pm 2.692$ & 2.346 & 14.390 & 3.079 & 0.903 & 13.058 \\
\hline MR & 96 & $77.252 \pm 41.902$ & 12.0 & 171.20 & 2.449 & 0.466 & 4.693 \\
\hline FR & 96 & $5.591 \pm 0.646$ & 4.209 & 6.499 & 2.451 & -0.823 & 12.047 \\
\hline PG & 96 & $746.136 \pm 1353.02$ & 2.254 & 4293.69 & 3.369 & 1.419 & 32.754 \\
\hline GDPPCG & 96 & $1.566 \pm 13.627$ & -50.236 & 91.673 & 24.242 & 2.083 & 1874.24 \\
\hline
\end{tabular}

Source: Authors' compilation

JB refers to the $\chi^{2}$ statistic from the Jarque-Bera test of normality

From the results of the Bayes estimate of different quantiles for all the countries in Table 3, there are some significant different percentiles in the conditional distribution of $\mathrm{CO}_{2}$ emissions from gaseous fuel consumption, $\mathrm{CO}_{2}$ emissions from liquid fuel consumption, $\mathrm{CO}_{2}$ emissions from residential buildings and commercial and public services, $\mathrm{CO}_{2}$ emissions from solid fuel consumption, $\mathrm{CO}_{2}$ emissions from transport, health expenditure, mortality rate and fertility rate. Also, $\mathrm{CO}_{2}$ emissions from gaseous fuel consumption has the expected sign but on only significant in $25^{\text {th }}$ quantile and this same trend was observed for health expenditure which has the expected sign and it was only significant at $90^{\text {th }}$ quantile. Other $\mathrm{CO}_{2}$ emission that was significant with the expected sign are $\mathrm{CO}_{2}$ emissions from liquid fuel consumption, $\mathrm{CO}_{2}$ emissions from residential buildings and commercial and public services, $\mathrm{CO}_{2}$ emissions from solid fuel consumption and $\mathrm{CO}_{2}$ emissions from transport. Initially, the coefficient of $\mathrm{CO}_{2}$ emission that was significant with the expected sign are $\mathrm{CO}_{2}$ emissions from liquid fuel consumption, $\mathrm{CO}_{2}$ emissions from residential buildings and commercial and public services, $\mathrm{CO}_{2}$ emissions from solid fuel consumption and $\mathrm{CO}_{2}$ emissions from transport slightly decreases then turns to slightly increase that is they all fluctuate throughout the quantile. There are highly significant differences across different percentiles in the conditional distribution of $\mathrm{CO}_{2}$ emission in this study. Furthermore, the increase in all the $\mathrm{CO}_{2}$ emission across Anglophone countries in West Africa affect their mortality rate which fluctuate throughout the quantile and as a result affect their life expectancy negatively. Fertility rate has a positive and significant effect on life expectancy among this countries and this was in agrees with the studies of $[1,3,6]$.

Table 3. The Bayes Estimate of different Quantiles for All the Countries ( $\tau=$ Quantile).

\begin{tabular}{|c|c|c|c|c|c|c|}
\hline \multirow{2}{*}{ Variables } & \multirow{2}{*}{ OLS } & \multicolumn{5}{|l|}{ Quantiles } \\
\hline & & $\tau=0.1$ & $\tau=0.25$ & $\tau=0.50$ & $\tau=0.75$ & $\tau=0.90$ \\
\hline $\mathrm{CO}_{2} \mathrm{EHP}$ & $0.029(1.000)$ & $-0.001(-0.027)$ & $-0.031(-1.137)$ & $-0.017(-0.459)$ & $0.049(1.028)$ & $0.060(0.529)$ \\
\hline $\mathrm{CO}_{2}-\mathrm{GFC}$ & $-0.092(-1.335)$ & $-0.093(-1.039)$ & $-0.150(-2.106)^{* *}$ & $-0.088(-0.924)$ & $-0.110(-0.389)$ & $0.008(0.009)$ \\
\hline $\mathrm{CO}_{2} \mathrm{LFC}_{\mathrm{C}}$ & $-0.253(-8.937)^{*}$ & $-0.148(-1.610)$ & $-0.239(-7.295)^{*}$ & $-0.266(-8.811)^{*}$ & $-0.281(-5.494)^{*}$ & $-0.312(1.225)$ \\
\hline $\mathrm{CO}_{2} \_\mathrm{MIC}$ & $-0.029(-0.869)$ & $0.000(0.003)$ & $0.038(1.236)$ & $0.023(0.601)$ & $-0.047(-0.906)$ & $-0.056(-0.451)$ \\
\hline $\mathrm{CO}_{2}$ OTHER & $0.013(0.575)$ & $0.026(1.524)$ & $0.003(0.261)$ & $0.002(0.131)$ & $0.009(0.514)$ & $-0.003(-0.223)$ \\
\hline $\mathrm{CO}_{2} \mathrm{RBCPS}$ & $-0.472(-4.301)^{*}$ & $-0.408(-0.962)$ & $-0.792(-5.662)^{*}$ & $-0.728(-4.223)^{*}$ & $-0.413(-2.280)^{* *}$ & $-0.512(-2.969)^{*}$ \\
\hline $\mathrm{CO}_{2}$ TRANS & $-0.139(-3.098)^{*}$ & $-0.235(-2.828)^{*}$ & $-0.097(-2.680)^{*}$ & $-0.127(-2.146)^{* *}$ & $-0.078(-0.458)$ & $-0.152(-0.482)$ \\
\hline $\mathrm{HE}$ & $0.166(0.564)$ & $0.019(0.045)$ & $0.380(1.658)$ & $0.377(1.271)$ & $0.165(0.386)$ & $0.634(1.776)^{* * *}$ \\
\hline MR & $-0.234(-8.205)^{*}$ & $-0.225(-4.615)^{*}$ & $-0.267(-12.097)^{*}$ & $-0.258(-6.864)^{*}$ & $-0.247(-1.990)^{* *}$ & $-0.193(-0.749)$ \\
\hline FR & $9.540(9.196)^{*}$ & $9.224(7.079)^{*}$ & $11.011(13.423)^{*}$ & $10.344(7.353)^{*}$ & $10.328(2.160)^{* *}$ & $8.133(0.698)$ \\
\hline PG & $-2.060(-0.102)$ & $3.470(0.891)$ & $-2.370(-1.420)$ & $-2.270(-1.150)$ & $-2.140(-0.555)$ & $-2.690(-0.513)$ \\
\hline GDPPCG & $0.022(0.798)$ & $0.030(0.603)$ & $0.017(1.037)$ & $0.015(0.674)$ & $0.002(0.098)$ & $0.024(1.083)$ \\
\hline Adjusted $\mathrm{R}^{2}$ & 0.499 & 0.339 & 0.432 & 0.393 & 0.288 & 0.210 \\
\hline
\end{tabular}

Source: Authors' compilation

The numbers in parentheses are t-statistics computed from heteroskedasticity-robust standard errors. Quantile regression results are based upon 1000 bootstrapping repetitions. The asterisks $* ; *$ and $* * *$ denote significance at the $1 \% ; 5 \%$ and $10 \%$ levels, respectively. OLS means ordinary least squares.

\section{Conclusions}

An estimated seven million people per year die from emission-related diseases. These include stroke and heart disease, respiratory illness and cancers. Many health-harmful emission pollutants also damage the climate and reducing emission pollution would save lives and help slow the pace of near-term climate change. This study investigated the environmental quality and its attendant effect on human health from Anglophone countries in West Africa over the 
period of 1990 to 2013 using panel quantile regression. The result obtained showed that the $\mathrm{CO}_{2}$ emission that can affect the health of Anglophone countries in West Africa are $\mathrm{CO}_{2}$ emissions from gaseous fuel consumption, $\mathrm{CO}_{2}$ emissions from liquid fuel consumption, $\mathrm{CO}_{2}$ emissions from residential buildings and commercial and public services, $\mathrm{CO}_{2}$ emissions from solid fuel consumption, $\mathrm{CO}_{2}$ emissions from transport. Other control variables that have influence on human health were health expenditure, mortality rate and fertility rate.

Therefore, the policy makers should implement policies (like energy conservation policies) that will control emission from gaseous fuel consumption, emissions from liquid fuel consumption, emissions from residential buildings and commercial and public services, emissions from solid fuel consumption and emissions from transport. Also, health sector has to be properly cater for by spending more on health and this can only increase the health outcomes in a country.

\section{References}

[1] Balan, F. (2016). Environmental quality and its human health effects: A causal analysis for the EU-25. International Journal of Applied Economics, 13 (1), 57-71.

[2] Odusanya, I. A., Adegboyega, S. B., \& Kuku, M. A. (2014). Environmental quality and health care spending in Nigeria. Fountain Journal of Management and Social Sciences, 3 (2), 57-67.

[3] Jerumeh, T. R., Ogunnubi, C. S., \& Yusuf, S. A. (2015). Industrial pollution and its attendant effects on public health in Nigeria. Journal of Economics and Sustainable Development, 6 (24), 164-175.

[4] Garbaccio, R. F., Mun, S., \& Jorgenson, D. W. (2000). The health benefits of controlling carbon emissions in china 75 . Ancillary Benefits and Costs of Greenhouse Gas Mitigation, 343.

[5] Van Zelm, R., Muchada, P. A., van der Velde, M., Kindermann, G., Obersteiner, M., \& Huijbregts, M. A. (2015). Impacts of biogenic $\mathrm{CO}_{2}$ emissions on human health and terrestrial ecosystems: the case of increased wood extraction for bioenergy production on a global scale. Gcb Bioenergy, 7 (4), 608-617.

[6] Matthew, O., Osabohien, R., Fagbeminiyi, F., Fasina, A. (2018). Greenhouse gas emissions and health outcomes in Nigeria: Empirical insight from ARDL technique. International Journal of Energy Economics and Policy, 8, 4350 .

[7] Munawer, M. E. (2018). Human health and environmental impacts of coal combustion and post-combustion wastes. Journal of Sustainable Mining, 17 (2), 87-96.

[8] Gaga, E. O., \& Ar1, A. (2019). Gas-particle partitioning and health risk estimation of polycyclic aromatic hydrocarbons (PAHs) at urban, suburban and tunnel atmospheres: Use of measured EC and $\mathrm{OC}$ in model calculations. Atmospheric Pollution Research, 10 (1), 1-11.

[9] Sulemana, I., McCann, L., \& James Jr, H. S. (2016). Perceived environmental quality and subjective well-being: are African countries different from developed countries? International Journal of Happiness and Development, 3 (1).

[10] Dhrifi, A. (2018). Does Environmental Degradation, Institutional Quality, and Economic Development Matter for Health? Evidence from African Countries. Journal of the Knowledge Economy, 1-16.

[11] Zaman, K., Ahmad, A., Hamzah, T. A. A. T., \& Yusoff, M. M. (2016). Environmental factors affecting health indicators in Sub-Saharan African countries: health is wealth. Social Indicators Research, 129 (1), 215-228.

[12] Zaidi, S., \& Saidi, K. (2018). Environmental pollution, health expenditure and economic growth in the Sub-Saharan Africa countries: Panel ARDL approach. Sustainable Cities and Society, 41, 833-840.

[13] Nkalu, C. N., \& Edeme, R. K. (2019). Environmental hazards and life expectancy in Africa: Evidence from GARCH Model. SAGE Open, 9 (1), 2158244019830500.

[14] Issaoui, F., Toumi, H., Touili, W. (2015). Effects of $\mathrm{CO}_{2}$ emissions on economic growth, urbanization and welfare: Application to Mena Countries (Munich Personal RePEc Archive [MPRA], Paper No. 65683). Retrieved from https://mpra.ub.uni-muenchen.de/65683/

[15] Assadzadeh, A., Faranak, B., Amir, S. (2014). The impact of environmental quality and pollution on health expenditures: A case study of petroleum exporting countries. Proceedings of 29th International Business Research Conference, Sydney, Australia, November 24-25, 2014.

[16] Egbichi, C., Abuh, O., Okafor, V., Godwin, A., Adedoyin, O. (2018). Dynamic impact of energy consumption on the growth of Nigeria economy (1986-2016): Evidence from symmetrical autoregressive distributed lag model. International Journal of Energy Economics and Policy, 8, 188-195.

[17] Koenker, R., \& Bassett Jr, G. (1978). Regression quantiles. Econometrica: journal of the Econometric Society, 33-50.

[18] Chen, M., \& Ching, M. (2000). A Statistical Analysis of Life Expectancy across Countries Using Multiple Regression. http://www.seas.upenn.edu/ ese302/Projects/Project_2.pdf

[19] Worldometers. (2019). Swaziland population data. http://www.worldometers.info/world-population/swazilandpopulation/. Accessed 8 Jan 2019. 